\title{
BLOCKCHAIN TECHNOLOGY APPLICATIONS: A LITERATURE REVIEW
}

\section{Marcelo Jasmim Meiriño marcelojm@id.uff.br \\ Fluminense Federal University - UFF, Niterói, Rio de Janeiro, Brazil.}

\section{Mirian Picinini Méxas}

mirianmexas@id.uff.br

Fluminense Federal University -

UFF, Niterói, Rio de Janeiro, Brazil.

\section{Alexandre do Valle Faria} avalle.faria@gmail.com

Fluminense Federal University -

UFF, Niterói, Rio de Janeiro, Brazil.

\section{Rodrigo Picinini Méxas}

rodrigopicinini@id.uff.br Fluminense Federal University UFF, Niterói, Rio de Janeiro, Brazil.

Geisa Drumond Meirelles meirellesdrumond@gmail.com Fluminense Federal University UFF, Niterói, Rio de Janeiro, Brazil.

\section{ABSTRACT}

Goal: The objective of this article is to raise the state of the art of the applications of blockchain described in the scientific literature.

Design/methodology/approach: A bibliographic research on the Scopus database was carried out from November, 2017 to May, 2018, supported by the scientific research technique called Bibliometry. The compilation of 102 articles found in the scientific literature were presented in the Blockchain context, providing a reference for the fields of blockchain applications.

Results: The results indicate a large increase in the number of articles published since 2017, the largest number of publications were written by authors affiliated with institutions located in China, as well as the most referenced applications are related to cryptocurrencies, smart contracts and loT.

Limitations of the investigation: The limitation lies in using only the Scopus database for bibliometry, despite being a renowned scientific base.

Practical implications: This study can serve as a bibliographic reference with a global view of the main Blockchain applications that can be applied by different types of organizations Originality/value: Blockchain is a technology that aims to securely store data, such as financial data, contracts, proof of identity, documents of possession, medical information, etc. To do so, a framework based on laws of mathematics and cryptography is used to ensure the security of transactions of different applications, such as Bitcoin, which is a digital currency that guarantees the safe transfer of financial data. However, being a new technology, there is still little research on the subject. On the other hand, there are different types of applications that are already benefiting from the blockchain structure.

Keywords: Blockchain Applications; Cryptocurrencies; Smart Contracts; IoT 


\section{INTRODUCTION}

Blockchain is a decentralized management technology of transactions and data, introduced in 2008, whose first application was the well-known Bitcoin crypto-data. The diversity of potential applications of the Blockchain technology and the embryonic state of research in this field has stimulated interest and publications in the subject. The embedded capability of such technology to provide security, anonymity and data integrity creates interesting research areas, especially from the perspective of technical challenges and limitations.

Kshetri (2017a) presents evidence that links the use of blockchain with the overcoming of some of the economic, social and political challenges faced by the Global South, besides highlighting the main applications and uses of blockchain in developing countries. It demonstrates how blockchain can help promote transparency, build trust and reputation, and increase transaction efficiency.

According to Mansfield-Devine (2017), blockchain has other applications far beyond the world of alternative currencies, and far beyond finance. In this sense, this study tries to answer in what way the applications of the Blockchain technology are organized.

In this research, a systematic mapping study of the literature was conducted with the objective of collecting all the relevant research on Blockchain applications. The core of this paper is to understand the current research topics, challenges and future directions of the Blockchain technology from the technical perspective. Therefore, it is hoped to establish a bibliographic reference that allows a global view of the existing methods in this scope and that can facilitate their understanding and application, both in the scientific field and in practice.

Most research is focused on revealing and improving the limitations of Blockchain from the privacy and security perspectives, but many of the proposed solutions need concrete evaluation of their effectiveness. Many other challenges related to the scalability of Blockchain, including its penetration into new business frontiers and its latency, have not been studied. Based on this study, the authors recommend that future research that may be provided to researchers seeking such topic be done.

Section 2 describes the concept of Blockchain in this article. Section 3 describes the research method applied in this review; Section 4 presents the results obtained in the literature research, with demonstrations of different spreadsheets and graphs; and finally Section 5 ends it with the conclusion.

\section{BLOCKCHAIN CONCEPTS}

Blockchain is defined as a List of Links, a Block Technology, with each block containing a number of transactions. This technology provides a decentralized and unchanging data storage system that can be used in a network of users. It can act as a shared ledger that records all transactions (Zhong et al., 2017)radio frequency identification (RFID and is used to create features.

Each transaction can be easily consulted, providing greater transparency and trust for all the stakeholders. Due to the fact that the original creator (or creators) is (are) anonymous, the real motives behind Blockchain are undisputedly unknown. However, it proved to be a more than adequate solution to the many issues. Taking into consideration that various clients (individuals or organizations) have a copy, which, in turn, needs to be consolidated and validated.

According to Kshetri (2017b) the Blockchain theme is presented as a technology that can provide a strong and robust cyber security solution and a high level of privacy protection. Its proponents argue that such technology is safe by design. In a blockchain-based model, there is no need to store information with third parties.

For many authors, part of the fascinating character of Blockchain derives from the fact that personal forum data must be viewed and accessed only with the permission of the real owner, and such information cannot be stored. The proof of identity (Kshetri, 2017a) - as such process is called - is stored in a cryptographic format, which makes it impossible or very difficult to compromise (Khan, 2017).

The security features of many of the important systems in many industries depend on the so-called "security through obscurity" approach (Kshetri, 2017a) in security engineering. The studies in such line aim to keep the security mechanisms and the implementation of the system in complete anonymity. However, a major disadvantage of such method is that the entire system can collapse when one finds out the security mechanism. A fact that is already known after several studies is that such practice becomes practically impossible when using the disruptive Blockchain technology.

\section{RESEARCH METHOD}

Research was done in the scientific literature with the objective of identifying the "state of the art" of Blockchain technology applications for the development of this work. Afterwards, a detailed analysis of the selected articles was carried out. Finally, the results were presented through summaries of the contents of the articles, tables and graphs. 
The research of the scientific literature on the subject was carried out based on the research technique called bibliometry, in which, according to Costa (2010), the SCOPUS database was used as the source. The research was carried out in two moments: the first in November - December, 2017 and the second in May, 2018.

The initial search on the Scopus database was performed from 11/02/2017 to 06/12/2017, using the keyword: "Blockchain", without restriction of year, finding 699 documents. Next, a filter was applied to the document type, considering Article, Article in Press, and Review, totalizing 211 documents. The titles and abstracts were then read, and 112 articles were selected and stored in the Mendeley tool.

One of the selected articles (Where Is Current Research on Blockchain Technology - A Systematic Review), by Yli-Huumo et al. (2016) deals with a systematic review of the literature, and has identified some applications of the use of Blockchain in other environments besides cryptocurrencies, such as: IoT, smart contracts, smart property, digital content distribution, botnet and P2P transmission protocols, demonstrating that the Blockchain technology is not limited to applications in cryptocurrencies.

Since the publication of Yli-Huumo et al. (2016) and being inspired by the distribution of clusters proposed by it, a new rereading of the 112 articles was performed, searching for the following types of Blockchain applications: Cryptocurrencies (Financial); Smart contracts; Smart property; and Digital content distribution. Then, 66 articles distributed in the following classification were selected: 9 Cryptocurrencies (Financial); 31 Smart contracts; 13 loT (Internet of Things); 1 Smart property; none Digital content distribution, and 12 others.

Table 1. Selected Articles on Blockchain in the Scopus database

\begin{tabular}{|c|c|c|c|c|c|c|}
\hline Keywords & $\begin{array}{l}\text { Records } \\
\text { Found }\end{array}$ & $\begin{array}{c}\text { Doc Type=Article } \\
\text { Article in Press, } \\
\text { Review }\end{array}$ & $\begin{array}{c}\text { Source- } \\
\text { Type= } \\
\text { Jounal }\end{array}$ & $\begin{array}{c}\text { Articles } \\
\text { selected } 2 \text { nd } \\
\text { search }\end{array}$ & $\begin{array}{c}\text { Articles } \\
\text { selected 1st } \\
\text { search }\end{array}$ & Total \\
\hline $\begin{array}{l}\text { "Blockchain" AND ("Cryptocur- } \\
\text { rency" OR "Cryptocurrencies") }\end{array}$ & 194 & 76 & 68 & 13 & 9 & $22(*)$ \\
\hline $\begin{array}{l}\text { "Blockchain" AND "Smart } \\
\text { contract" }\end{array}$ & 231 & 74 & 64 & 17 & 31 & $\begin{array}{c}48(*) \\
(* *)\end{array}$ \\
\hline $\begin{array}{c}\text { "Blockchain" AND } \\
\text { ("IoT" OR “Internet of Things") }\end{array}$ & 178 & 41 & 38 & 10 & 13 & $23(* *)$ \\
\hline $\begin{array}{l}\text { "Blockchain" AND } \\
\text { "Smart property" }\end{array}$ & 4 & 2 & 2 & 0 & 1 & 1 \\
\hline $\begin{array}{c}\text { "Blockchain" AND } \\
\text { "Digital content distribution" }\end{array}$ & 0 & 0 & 0 & 0 & 0 & 0 \\
\hline Other articles found & 0 & 0 & 0 & 0 & 12 & 12 \\
\hline TOTAL & & & & 40 & 66 & 106 \\
\hline$(*) 1$ articles in common & & & & & & 105 \\
\hline$(* *) 2$ articles in common & & & & & & 102 \\
\hline
\end{tabular}

Source: The authors themselves
Aiming to update this research, a second stage of the scientific literature was carried out in the Scopus database between 05/05/2018 and 05/27/2018. Table 1 presents the consolidated results of the two phases of the research considering the groupings.

Table 1 shows the keywords used in the second step. For the first search, the keywords used were: "Blockchain" AND ("Cryptocurrency" OR "Cryptocurrencies"), finding 194 documents. In order to restrict such search, filters by Document Type were applied, and the following types were considered in the research: Article, Article in Press, Review; and later, filters were applied by Source Type, considering only the Journal, obtaining 68 documents. The titles and abstracts were then read, and 13 articles were selected, which added to the 9 articles collected in the first round of research, totalizing 22 .

For the other searches, the same criteria described previously were used, and the results are presented in Table 1, totalizing 106 articles. Four out of the 106 articles were common among the types of applications, as observed in Table 1, thus obtaining 102 different articles to be considered in this study.

The main results of this literature review are described below.

\section{RESULTS}

\section{Analysis by year of publication}

Figure 1 presents an overview of the records found in the research by year of publication. There is an increase 
in publications on Blockchain applications from 2017 onwards. The year of 2018 presents partial and already considerable results, since the survey analyzed articles until May of that year.

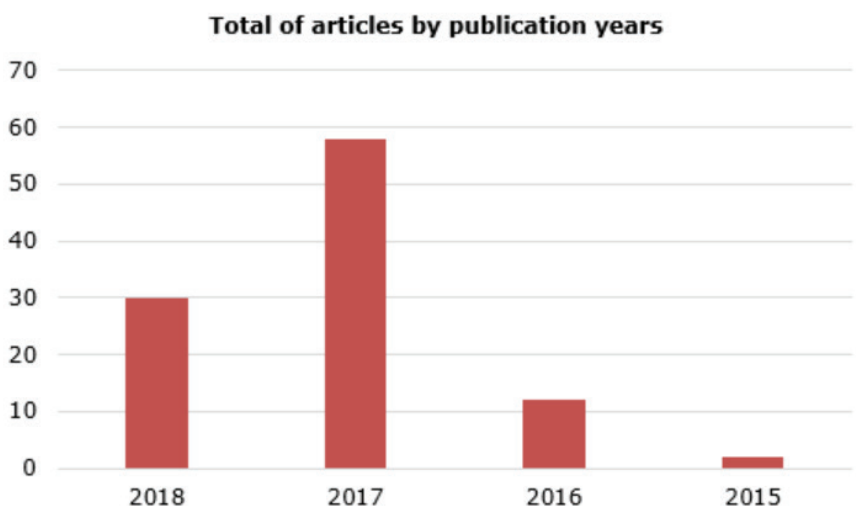

Figure 1. Distribution of articles by publication year. Source: The authors themselves

According to Tan et al. (2018), the global blockchain technology market is expected to be worth 13.96 billion dollars by 2022 , along with a compound annual growth rate of $42.8 \%$ over the forecasted period. Blockchain is a decentralized network that can record transactions between two parties. Blockchain solutions are increasingly being used in a number of sectors including Banking, Financial Services and Insurance (BFSI), the government and the public sector, health and life sciences, retail and e-commerce, automotive, media and entertainment, among others. The demand for blockchain solutions is increasing rapidly as it helps to improve efficiency and reduce the cost of transaction processing.

\section{ANALYSIS BY PERIODICAL PUBLICATIONS}

In Table 2 it is possible to see the 60 different titles from journals in which the 102 articles that deal with the research problem are published. Table 2 also shows the frequency of records found by journal titles. By analyzing this table, it is possible to conclude that the three periodicals that published more articles on blockchain applications were: IEEE Access; Zhongguo Dianji Gongcheng Xuebao / Proceedings of the Chinese Society of Electrical Engineering; and Strategic Change.
Table 2. Distribution of articles by journals

\begin{tabular}{|c|c|}
\hline Journal & Frequency \\
\hline IEEE Access & 11 \\
\hline $\begin{array}{l}\text { Zhongguo Dianji Gongcheng Xuebao/Proceedings } \\
\text { of the Chinese Society of Electrical Engineering }\end{array}$ & 9 \\
\hline Strategic Change & 5 \\
\hline Future Generation Computer Systems & 3 \\
\hline IEEE Communications Magazine & 3 \\
\hline IEEE Spectrum & 3 \\
\hline Metaphilosophy & 3 \\
\hline Applied Energy & 2 \\
\hline Computer & 2 \\
\hline Computer Law \& Security Review & 2 \\
\hline Computer Science - Research and Development & 2 \\
\hline Dianli Jianshe/Electric Power Construction & 2 \\
\hline Dianwang Jishu/Power System Technology & 2 \\
\hline F1000 Research & 2 \\
\hline First Monday & 2 \\
\hline IEEE Internet of Things Journal & 2 \\
\hline Sustainability (Switzerland) & 2 \\
\hline Zidonghua Xuebao/Acta Automatica Sinica & 2 \\
\hline Others (42 periodicals with one publication each) & 42 \\
\hline TOTAL & 102 \\
\hline
\end{tabular}

Source: The authors themselves

Analysis by nationality of the authors' affiliation institutions

Figure 2 shows the geographical distribution of the institutions / organizations that the authors of the selected articles are bound by.

There is a noticeably higher number of publications in the Chinese Institutions. The great volume of institutions and researchers of that country involved with the theme finds similarity with the interest the increasing number of applications and uses of the technology developed in that country.

Glance Technologies Inc. is also listed on the CHINA Securities Exchange under the Ticker (CSE: GET). Recently, the company has announced the latest news that "the next Ticket Pay feature is available on its Glance Pay platform, demonstrating even more the flexibility, value and applicability of the platform in a wide variety of payment scenarios. The initial resource will enable the users to pay for the parking". Users will be allowed to use the digital mechanism based on the Blockchain technology at the time of receiving the ticket, simply by taking a photo of it through the Glance Pay application and confirming the amount paid, thus reducing the hassle for consumers and potentially saving significant money due to the elimination of late payment fees and possibly vehicle impounding fees. Glance is exploring the potential of applying this to other types of tickets, such as traffic violations. 


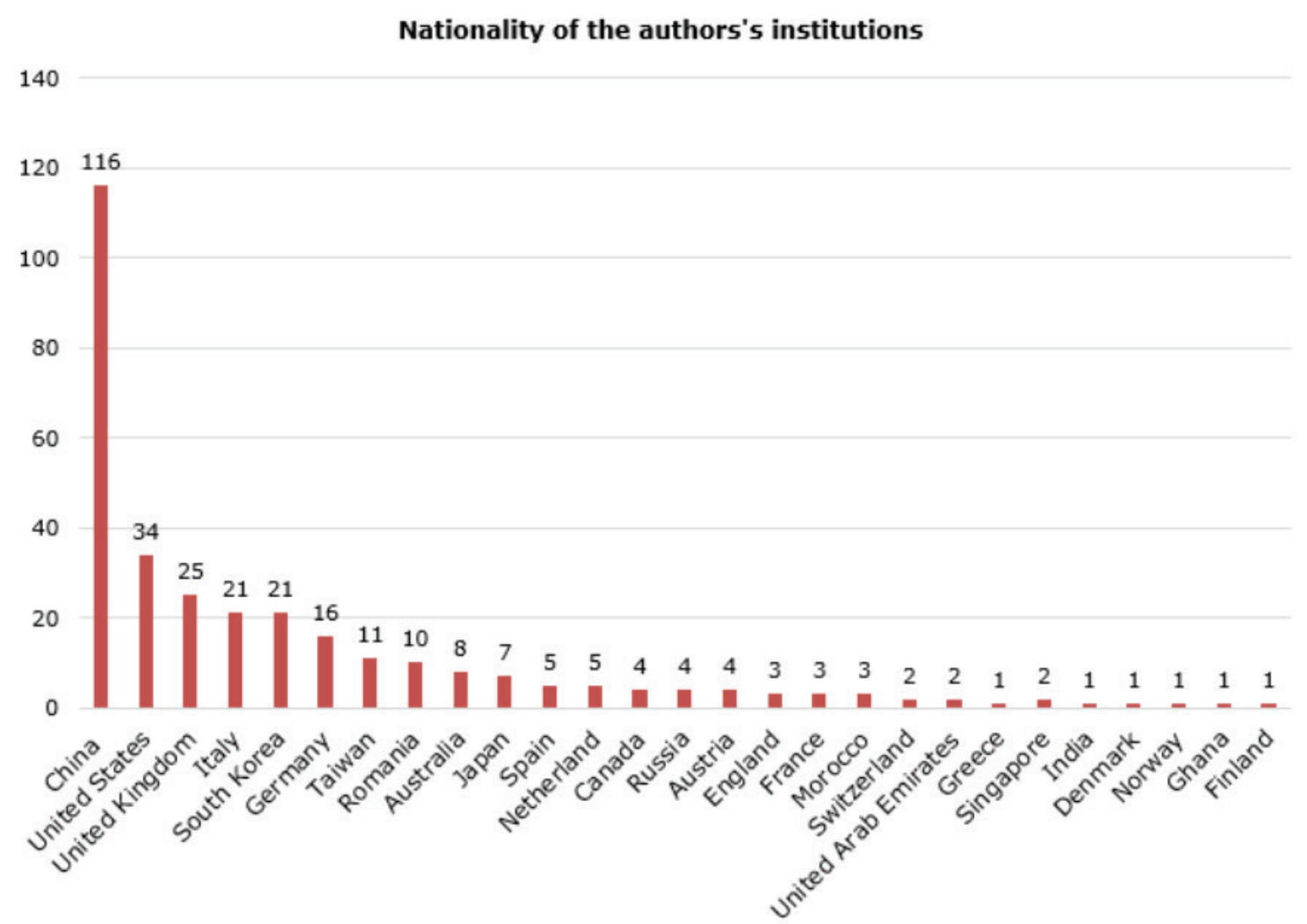

Figure 2. Distribution of articles by the nationality of the authors' affiliation institution. Source: The authors themselves

\section{Analysis by type of Blockchain applications}

The articles collected in the scientific literature were grouped into four categories of applications, according to Table 3 below.

Table 3. Distribution of articles by four-application categories

\begin{tabular}{|c|c|}
\hline Application types & Number of articles \\
\hline Cryptocurrencies & 22 \\
\hline Smart contracts & 48 \\
\hline Internet of Things & 23 \\
\hline Others (including Smart property) & 13 \\
\hline
\end{tabular}

Source: The authors themselves

It is worth mentioning that according to Miau and Yang (2018), the number of searches on Blockchain in the literature has been increasing and three different phases have been identified: from 2008 to 2013, the topics were related to Bitcoin and Cryptocurrencies; from 2014 to 2015, the number of literature articles on Bitcoin has grown rapidly; after 2016, many researchers are aware of the techniques of blockchain and smart contract.

\section{Application 01: Financial (Cryptocurrencies)}

The financial systems that the general public is accustomed to dealing with on their regular days tend to be problematic, error-prone, and often extremely slow. Intermediaries are often needed to mediate the process and resolve conflicts. Of course, such actions generate stress and waste of time and money. In contrast, users find blockchain cheaper, more transparent and more effective. It is no wonder that an increasing number of financial services are using the blockchain system to introduce innovations such as smart bonds and smart contracts. The former ones are automatically paid to the bond holders once certain preprogrammed terms are met. The latter ones are digital contracts that are self-executing and are maintained when the terms are met.

Some applications are already being implemented in the market today, such as Asset Management, in which traditional trading processes in the management of assets and the parties that negotiate and manage the assets can be expensive and risky, particularly when dealing with international transactions.

Insurance management in general is another widely used aspect and has been increasingly adhering to the use of Blockchain. Managing and processing complaints can be a frustrating and ungrateful procedure. Insurance processors 
need to go through fraudulent claims, fragmented data sources - and they need to process such forms manually. The room for error is huge. Blockchain provides a system for risk-free management and transparency. Its encryption properties allow insurance companies to capture the asset ownership to be insured with $100 \%$ certainty according to the provided and requested information, as exemplified by Samantha Stein (2018) in her article for the digital magazine TechCrunch.

Table 4 below shows the 22 selected articles on blockchain applications using cryptocurrencies.

\section{Application 02: Smart contracts}

Smart contracts connect blockchain to the real world. Such contracts allow you to open the front door, turn on your washing machine, charge your electric vehicle or send funds abroad - all without lifting a finger.

On a larger scale, such technology could ensure voting, updating medical records and accelerating supply chains.
They can be the key to decentralization and a reliable mechanism to transact almost any type of business through blockchain, including cryptocurrency negotiations.

The term "smart contract" was first coined in 1996 by Nick Szabo, a computer scientist and cryptographer. He defined a smart contract as: “... a set of promises, specified in the digital form, including protocols within which the parties perform these promises" (Gord, 2016).

In other words, a smart contract is a piece of code in blockchain that performs an action when certain criteria are met. They allow a much more complex programming within a logic. After the action is performed, it is added to blockchain as a permanent record.

As Sundhararajan et al. (2018) mention in their article, the main activities and resources of the blockchain technology are "decentralization" and "distrust." As a distributed accounting technology, a smart contract infrastructure platform and a disruptive computing paradigm, blockchain can effectively generate programmable currency, programmable financing and build a programmable society, which will have

Table 4. Relation of articles with Cryptocurrency applications

\begin{tabular}{|c|c|}
\hline Area of application & Authors / Year \\
\hline Finance / Cryptocurrencies & $\begin{array}{c}\text { Zamani and Giaglis (2018); Berentsen and Schar (2018); Kang et al. (2018); Gomber et al. (2018); } \\
\text { Ziegeldorf et al. (2018); Legotin et al. (2018); Wang et al. (2018); Ying et al. (2018); Giungato et al. } \\
\text { (2017)Scott et al. (2017); Ducas and Wilner, (2017); Dai and Vasarhelyi (2017); Hayes (2017); Goertzel } \\
\text { et (2017); Huckle et al. (2017); Eyal (2017); Cocco et al., (2017); Brühl (2017); Krainer ( 2017); } \\
\text { Nordrum (2017); Tschorsch (2016) }\end{array}$ \\
\hline Bitcoin and Smart Contract & Yuan and Wang (2016) \\
\hline
\end{tabular}

Source: The authors themselves

Table 5. List of articles with Smart Contract applications

\begin{tabular}{|c|c|}
\hline $\begin{array}{c}\text { Area of application } \\
\begin{array}{c}\text { Legal / Audit / Subscription } \\
\text { Payments }\end{array}\end{array}$ & $\begin{array}{c}\text { Savelyev (2018); Yuan et al. (2018); Governatori et al. (2018); Rozario and Vasarhelyi (2018); Zhao et } \\
\text { al. (2018); Lemieux (2016); De Filippi and Hassan (2016); Pachaiyappan and Kasturi (2018) }\end{array}$ \\
\hline Health & $\begin{array}{r}\text { Dagher et al. (2018); Borioli and Couturier (2018); Mannaro et al. (2018); Irving and Holden (2017); } \\
\text { Xia et al. (2017); Yue et al. (2016); Zhang et al. (2016); Nugent et al. (2016) }\end{array}$ \\
\hline Energy & $\begin{array}{r}\text { Zhang et al. (2016); Park et al., 2018); Gao et al.(2018); Li et al. (2018); Pop et al. (2018); Li, Caoet al. } \\
\text { (2017);Ouyang et al. (2017); Yang et al. (2017); Ping et al. (2017); Tai et al. (2016) }\end{array}$ \\
\hline Cruz et al. (2018); Kim and Hong (2016)
\end{tabular}


a far-reaching impact on the financial and other fields, and will lead to a new round of technological and application change. Although the blockchain technology can improve efficiency, reduce costs, and increase data security, it is still a serious privacy issue that has made the researchers widely preoccupied.

Table 5 below presents the 48 selected articles on blockchain applications using smart contracts.

\section{Application 03: IoT}

Blockchain has stood out in a context of Internet of Things. Blockchains have many benefits. They are not the answer to all the challenges of the digital economy as it is sometimes said, but it is certain that they will play a growing role in the Internet of Things. To illustrate the benefits of the convergence between blockchain and the Internet of Things, IBM sets the example of complex trade routes and logistics through which smart contracts can track (and register via blockchain technology) everything that happened to individual items and packages. The benefits: audit trails, accountability, new forms of contracts and speed, to name a few.

Other actions are being justified when IoT and Blockchain are correlated. Insecure "Internet of Things" devices have already contributed to major cyber disasters such as the October 2016 cyber-attack on Dyn, an Internet routing company that knocked over 80 popular sites and stalled the Internet traffic in the US. In a paper, Findlay (2017) comments that the solution to the problem lies in the technology of "internet of things" and in the blockchain and cyber-security systems, where the use of such technology, combined with the advances in connective technology, could be a new way to track and distribute security software updates using blockchains. Table 6 presents the 23 selected articles on blockchain applications using loT.

\section{Application 04: Others}

Other applications are already being developed with such technology and some can be mentioned as being innovative, such as: Voting mechanisms; Trading of commodities, from oil to soy; Sharing of solar energy; Tracking of dental records; Creation of Games; Project management, etc.

All that work is allowing people to rely on digital relationships previously considered impossible. Data are being released, protected and recorded in a different way. Such procedure is changing digital relationships, creating the capacity of being automated in the code through "smart contracts", via Blockchain.

An identity in a common format as we know it nowadays, but being developed in a digital format based on the blockchain of a property, can include the history, location and details of the final document, helping with the online and definite information. Typically, buyers and banks can potentially rely on such digital identity of property for title assessment, since any change in the existing data would have to occur through a consensus among multiple blockchain nodes.

In addition, the distributed, tamper-proof and encrypted nature of the blockchain will likely make it difficult for criminals to commit fraud related to liens, easements, air and subsurface rights, titles or transfers. This increased security and transparency can mitigate the risk of title frauds and reduce costs by simplifying the title verification process. A more digitized and transparent process can also speed up the transfer of titles, use the title as collateral and reduce the total transaction time. In fact, some governments around the world are planning to use the blockchain platform for a broader social impact, since property title registrations have the potential to reduce corruption and improve transparency over land ownership.

Table 6. List of articles with loT applications

\begin{tabular}{|c|c|}
\hline Area of application & Authors/Year \\
\hline Commercial & Grewal et al. (2018); Kshetri (2017a); Dorri et al. (2017); Toyoda et al. (2017)RFID (Radio Frequency \\
IDentification; Kshetri (2017b)
\end{tabular}


Table 7. List of articles with other applications

\begin{tabular}{|c|c|}
\hline Area of application & Authors/Year \\
\hline Energy & $\begin{array}{c}\text { Mengelkamp et al. (2017); Wu et al. (2017); Zeng et al. (2017); She et al. (2017); Yang et al. (2017); } \\
\text { Mengelkamp et al. (2017a); Knirsch et al., (2017); Peck and Wagman (2017); Zhang et al. ( 2016) }\end{array}$ \\
\hline $\begin{array}{c}\text { Commercial } \\
\text { Smart Property /Artificial } \\
\text { intelligence }\end{array}$ & van Engelenburg et al. (2017) \\
\hline
\end{tabular}

Source: The authors themselves

Intellectual property laws, such as patents and copyrights, are premised on the theory of incentive. To encourage people to create, they actually receive a monopoly (with a few exceptions) on their creations and can go to court and prevent others from taking over the work.

The digital world has made the tension between innovators and free riders even more acute. In the pre-digital age, copying a book involved considerable costs to the copying.

However, theory does not always match reality. History is replete with examples of patents that cause more harm than innovation.

In an article, the researchers Kewell et al. (2017) make an analogy with James Watt's steam engine that was an advance over existing steam engines, but such technology could not be built because of Watt's patents. It was not until the patents expired - one of which had been inexplicably extended by the Parliament - that steam energy came on its own when it impelled the industrial revolution.

We should not be surprised that patent laws can undermine innovation. The British Crown used patents to increase revenues and patents were granted on behalf of the common good, such as salt.

Table 7 presents the 13 selected articles on other blockchain applications, including those of Smart property.

\section{CONCLUSION}

The present study carried out a systematic review of the literature with the objective of collecting information about Blockchain applications, based on the access to the Scopus database, from the Capes Journal Portal. A total of 102 articles were selected from 60 different journals, followed by a classification system: chronological evolution of publication; publications in periodicals; countries of the authors' affiliation institutions; and the type of Blockchain application.

As a result of this research, it is observed an increase of publications on Blockchain applications from 2017, as well as in the year 2018 that, despite presenting partial results until May / 2018, shows a considerable growth of articles on such topic.

In relation to the 60 journals, it is possible to conclude that the three journals that published more articles on blockchain applications were: IEEE Access; Zhongguo Dianji Gongcheng Xuebao / Proceedings of the Chinese Society of Electrical Engineering; and Strategic Change, all of them adding up to a total of $24.5 \%$.

As for the geographical distribution, most of the authors' affiliations are linked to institutions located in China, followed by the United States and the United Kingdom. Another conclusion is that most articles have focused on smart contract applications, corresponding to $47 \%$ of the total, followed by internet of things, cryptocurrencies and others. It is worth mentioning that smart contracts are being used in the health, legal, and energy areas, among others. IoT applications are being used in commercial, city development / intelligent transportation areas, among others.

It is expected that the present work can serve as a bibliographic reference with a global view of the main Blockchain applications. As a proposal for future research, it is suggested to carry out an in-depth analysis of the blockchain applications used in the reviewed studies, in order to support decision makers in the selection of the best blockchain application solutions.

\section{Financing}

The research was supported by the Brazilian National Council for Scientific and Technological Development (CNPq) - Universal Call 01-2016, Process Number: 430119/2016-0; and FOPESQ Call 2017 Proppi UFF.

\section{REFERENCES}

Berentsen, A.; Schar, F. (2018), 'A Short Introduction to the World of Cryptocurrencies', Review, Vol. 100, No. 1, pp. 1-19. doi: 10.20955/r.2018.1-16. 
Brazilian Journal of Operations \& Production Management

Volume 16, Número 4, 2019, pp. 672-684

DOI: 10.14488/BJOPM.2019.v16.n4.a12
Borioli, G. S.; Couturier, J. (2018), 'How blockchain technology can improve the outcomes of clinical trials', British Journal of Health Care Management, Vol. 24, No. 3, pp. 156-162. doi: 10.12968/bjhc.2018.24.3.156.

Brühl, V. (2017), 'Bitcoins, Blockchain und Distributed Ledgers', Wirtschaftsdiens, Vol. 97, No. 2, pp. 135-142. doi: 10.1007/s10273-017-2096-3.

Cha, S. C. et al. (2018), 'A Blockchain Connected Gateway for BLE-based Devices in the Internet of Things', IEEE Access, Vol. 6, pp. 24639-24649. doi: 10.1109/ACCESS.2018.2799942.

Cha, S.-C. et al. (2017), 'On the Design of a Blockchain-Based Reputation Service for Android Applications', Advanced Science Letters, Vol. 23, No. 3, pp. 2179-2184. doi: 10.1166/ asl.2017.8592.

Christidis, K.; Devetsikiotis, M. (2016), 'Blockchains and Smart Contracts for the Internet of Things', IEEE Access, Vol. 4, pp. 2292-2303. doi: 10.1109/ACCESS.2016.2566339.

Cocco, L. et al. (2017), 'Banking on blockchain: Costs savings thanks to the blockchain technology', Future Internet, Vol. 9, No. 3, pp. 1-20. doi: 10.3390/fi9030025.

Costa, H. G. (2010), 'Modelo para Webibliomining: proposta e caso de aplicação', Revista FAE, Vol. 12, No. 1, pp. 115-125.

Cruz, J. P. et al.(2018), 'Special Sectionon Research Challengesand Opportunitiesin Securityand RBAC-SC : Role-Based Access Control Using Smart Contract', IEEE accesss, Vol. 6, pp. 12240-12251. doi: 10.1109/ACCESS.2018.2812844.

Cuccuru, P. (2017), 'Beyond bitcoin: an early overview on smart contracts', International Journal of Law and Information Technology, Vol. 25, No. 3, pp. 179-195. doi: 10.1093/ ijlit/eax003.

Dagher, G. G. et al. (2018), 'Ancile: Privacy-preserving framework for access control and interoperability of electronic health records using blockchain technology', Sustainable Cities and Society, Vol. 39, pp. 283-297. doi: 10.1016/j. scs.2018.02.014

Dai, J.; Vasarhelyi, M. A. (2017), 'Toward blockchain-based accounting and assurance', Journal of Information Systems, Vol. 31, No. 3, pp. 5-21. doi: 10.2308/isys-51804.

Delgado-Segura, S. et al.(2017), 'A fair protocol for data trading based on Bitcoin transactions', Future Generation Computer Systems. doi: 10.1016/j.future.2017.08.021.

Dorri, A. et al. (2017), 'BlockChain: A Distributed Solution to Automotive Security and Privacy', IEEE Communications Magazine, Vol. 55, No. 12, pp. 119-125. doi: 10.1109/ MCOM.2017.1700879.

Ducas, E.; Wilner, A. (2017), 'The security and financial implications of blockchain technologies: Regulating emerging technologies in Canada', International Journal, Vol. 72, No. 4, pp. 538-562. doi: 10.1177/0020702017741909.
Dupont, Q. (2017), 'Blockchain Identities: Notational Technologies for Control and Management of Abstracted Entities', Metaphilosophy, Vol. 48, No. 5, pp. 634-653. doi: 10.1111/ meta.12267.

van Engelenburg, S. et al. (2017), 'Design of a software architecture supporting business-to-government information sharing to improve public safety and security', Journal of Intelligent Information Systems. doi: 10.1007/s10844-0170478-z.

Eyal, I. (2017), 'Blockchain Technology: Transforming Libertarian Cryptocurrency Dreams to Finance and Banking Realities', Computer, Vol. 50, No. 9, pp. 38-49. doi: 10.1109/ MC.2017.3571042.

De Filippi, P.; Hassan, S. (2016), 'Blockchain technology as a regulatory technology: From code is law to law is code', First Monday, Vol. 21, No. 12. doi: 10.5210/fm.v21i12.7113.

Findlay, C. (2017), 'Participatory cultures, trust technologies and decentralisation: innovation opportunities for recordkeeping', Archives and Manuscripts, Vol. 45, No. 3, pp. 176-190. doi: 10.1080/01576895.2017.1366864.

Gao, J. et al. (2018), 'GridMonitoring: Secured Sovereign Blockchain Based Monitoring on Smart Grid', IEEE Access, Vol. 6, pp. 9917-9925. doi: 10.1109/ACCESS.2018.2806303.

Giungato, P. et al. (2017), 'Current trends in sustainability of bitcoins and related blockchain technology', Sustainability, Vol. 9, No. 12. doi: 10.3390/su9122214.

Goertzel, B. et al. (2017), 'The global brain and the emerging economy of abundance: Mutualism, open collaboration, exchange networks and the automated commons', Technological Forecasting and Social Change, Vol. 114, pp. 65-73. doi: 10.1016/j.techfore.2016.03.022.

Gomber, P. et al. (2018), 'On the Fintech Revolution: Interpreting the Forces of Innovation, Disruption, and Transformation in Financial Services', Journal of Management Information Systems, Vol. 35, No. 1, pp. 220-265. doi: 10.1080/07421222.2018.1440766.

Gord, M. (2016), 'Smart Contracts Described by Nick Szabo 20 Years Ago Now Becoming Reality', available at: https:// bitcoinmagazine.com/articles/smart-contracts-described-by-nick-szabo-years-ago-now-becoming-reality-1461693751/ (access 7 Jan. 2018).

Governatori, G. et al. (2018), 'On legal contracts, imperative and declarative smart contracts, and blockchain systems', Artificial Intelligence and Law, pp. 1-33. doi: 10.1007/s10506018-9223-3.

Grewal, D. et al. (2018), 'The Evolution and Future of Retailing and Retailing Education', Journal of Marketing Education, Vol. 40, No. 1, pp. 85-93. doi: 10.1177/0273475318755838.

Hayes, A. S. (2017), 'Cryptocurrency value formation: An empirical study leading to a cost of production model for va- 
luing bitcoin', Telematics and Informatics, Vol. 34, No. 7, pp. 1308-1321. doi: 10.1016/j.tele.2016.05.005.

Herbaut, N.; Negru, N. (2017), 'A Model for Collaborative Blockchain-Based Video Delivery Relying on Advanced Network Services Chains', IEEE Communications Magazine, Vol. 55, No. 9, pp. 70-76. doi: 10.1109/MCOM.2017.1700117.

Herian, R. (2017), 'Blockchain and the (re)imagining of trusts jurisprudence', Strategic Change, Vol. 26, No. 5, pp. 453-460. doi: 10.1002/jsc.2145.

Huckle, S. et al. (2017), 'Towards a post-cash society: An application to convert fiat money into a cryptocurrency by', First Monday, Vol. 22, No. 3. Available at: https://www.scopus.com/inward/record.uri?eid=2-s2.0-85014479815\&partn erID $=40 \& m d 5=a 57 a 869 a 95 e c 09 c 9 c e 8370819 d 1 d 3522$ (access 7 Jan. 2018)

Hughes, K. (2017), 'Blockchain, The Greater Good, and Human and Civil Rights', Metaphilosophy, Vol. 48, No. 5, pp. 654-665. doi: 10.1111/meta.12271.

Irving, G.; Holden, J. (2017), 'How blockchain-timestamped protocols could improve the trustworthiness of medical science', F1000Research, Vol. 5, p. 222. doi: 10.12688/f1000research.8114.3.

Ishmaev, G. (2017), 'Blockchain Technology as an Institution of Property', Metaphilosophy, Vol. 48, No. 5, pp. 666686. doi: 10.1111/meta.12277.

Kang, J. M. et al. (2018), 'A study on privacy protection method applying blockchain technology for big data utilization (focus on the blockchain technology for monero, dash and Z-cash to ensure anonymity)', Journal of Engineering and Applied Sciences, Vol.13, No. 3, pp. 691-695. doi: 10.3923/ jeasci.2018.691.695.

Kewell, B. et al. (2017), 'Blockchain for good?', Strategic Change, Vol. 26, No. 5, pp. 429-437. doi: 10.1002/jsc.2143.

Khan, A. (2017), ‘Bitcoin's Billion Dollar Baboon: An Initial Coin Offering (ICO) Attracts Big Time Talent', available at: https://www.huffingtonpost.com/entry/ bitcoins-billion-dollar-baboon-an-initial-coin-offering us_595bc961e4b0f078efd98cb3(access 7 Jan. 2018)

Kim, K. J.; Hong, S. P. (2016), 'Study on rule-based data protection system using blockchain in P2P distributed networks', International Journal of Security and its Applications,Science and Engineering Research Support Society, Vol. 10, No. 11, pp. 201-210. doi: 10.14257/ijsia.2016.10.11.18.

Knirsch, F. et al. (2017), 'Privacy-preserving blockchain-based electric vehicle charging with dynamic tariff decisions', Computer Science - Research and Development, pp. 1-9. doi: 10.1007/s00450-017-0348-5.

Krainer, R. E. (2017), 'Economic stability under alternative banking systems: Theory and policy', Journal of Financial Stability, Vol. 31, pp. 107-118. doi: 10.1016/j.jfs.2017.05.005.
Kshetri, N. (2017a), 'Blockchain's roles in strengthening cybersecurity and protecting privacy', Telecommunications Policy, pp. 1-12. doi: 10.1016/j.telpol.2017.09.003.

Kshetri, N. (2017b), 'Can Blockchain Strengthen the Internet of Things?', IT Professional, Vol. 19, No. 4, pp. 68-72. doi: 10.1109/MITP.2017.3051335.

Lee, B.; Lee, J.-H. (2017), 'Blockchain-based secure firmware update for embedded devices in an Internet of Things environment', The Journal of Supercomputing, Vol. 73, No. 3, pp. 1152-1167. doi: 10.1007/s11227-016-1870-0.

Lee, S. H.; Yang, C. S. (2018), 'Fingernail analysis management system using microscopy sensor and blockchain technology', International Journal of Distributed Sensor Networks, Vol. 14, No. 3. doi: 10.1177/1550147718767044.

Legotin, F. Y. et al. (2018), 'Prospects for crypto-currency and blockchain technologies in financial markets', Espacios, Vol. 39, No. 19.

Lei, A. et al. (2017), 'Blockchain-Based Dynamic Key Management for Heterogeneous Intelligent Transportation Systems', IEEE Internet of Things Journal, Vol. 4662, No.c, pp. 1-12. doi: 10.1109/JIOT.2017.2740569.

Lemieux, V. L. (2016), 'Trusting records: is Blockchain technology the answer?', Records Management Journal, Vol. 26, No. 2, pp. 110-139. doi: 10.1108/RMJ-12-2015-0042.

Li, B. et al. (2017), 'Overview of application of block chain technology in ancillary service market', Dianwang Jishu/ Power System Technology, Vol. 41, No. 3, pp. 736-744. doi: 10.13335/j.1000-3673.pst.2016.1179.

Li, B. et al. (2017), 'A Preliminary Study of Block Chain based Automated Demand Response System', Zhongguo Dianji Gongcheng Xuebao/Proceedings of the Chinese Society of Electrical Engineering, Vol. 37, No. 13, pp. 3691-3702. doi: 10.13334/j.0258-8013.pcsee.162462.

Li, G. et al. (2018), 'Energy management analysis and scheme design of microgrid based on blockchain', Dianli Jianshe/ Electric Power Construction, Vol. 39, No. 2, pp. 43-49. doi: 10.3969/j.iisn.1000-7229.2018.02.006.

Mannaro, K. et al. (2018), 'A blockchain approach applied to a teledermatology platform in the Sardinian Region (Italy)', Information (Switzerland), Vol. 9, No. 2. doi: 10.3390/ info9020044.

Mansfield-Devine, S. (2017), 'Beyond Bitcoin: using blockchain technology to provide assurance in the commercial world', Computer Fraud \& Security, Vol. 2017, No. 5, pp. 14-18. doi: 10.1016/S1361-3723(17)30042-8.

McConaghy, M. et al. (2017), 'Visibility and digital art: Blockchain as an ownership layer on the Internet', Strategic Change, Vol. 26, No. 5, pp. 461-470. doi: 10.1002/jsc.2146. 
Brazilian Journal of Operations \& Production Management

Volume 16, Número 4, 2019, pp. 672-684

DOI: 10.14488/BJOPM.2019.v16.n4.a12
Mengelkamp, E. et al. (2017a), 'Designing microgrid energy markets: A case study: The Brooklyn Microgrid', Applied Energy, Vol. 210, pp. 870-880. doi: 10.1016/J.APENERGY.2017.06.054.

Mengelkamp, E. et al. (2017b), 'Softwarization of Internet of Things Infrastructure for Secure and Smart Healthcare', Computer, Vol. 50, No. 7, pp. 74-79. doi: 10.1109/MC.2017.195.

Mengelkamp, E. et al. (2017), 'A blockchain-based smart grid: towards sustainable local energy markets', Computer Science - Research and Development, pp. 1-8. doi: 10.1007/ s00450-017-0360-9.

Miau, S.; Yang, J.-M. (2018), 'Bibliometrics-based evaluation of the Blockchain research trend: 2008 - March 2017', Technology Analysis \& Strategic Management, pp. 1-17. doi: 10.1080/09537325.2018.1434138.

Nordrum, A. (2017), 'Govern by blockchain dubai wants one platform to rule them all, while Illinois will try anything', IEEE Spectrum, Vol. 54, No. 10, pp. 54-55. doi: 10.1109/MSPEC.2017.8048841.

Novo, O. (2018), 'Blockchain Meets IoT: an Architecture for Scalable Access Management in IOT', IEEE Internet of Things Journal, Vol. 5, No. 2, pp. 1184-1195. doi: 10.1109/ JIOT.2018.2812239.

Nugent, T. et al. (2016), 'Improving data transparency in clinical trials using blockchain smart contracts', F1000Research, Vol. 5(May), p. 2541. doi: 10.12688/f1000research.9756.1.

O'Dair, M.; Beaven, Z. (2017), 'The networked record industry: How blockchain technology could transform the record industry', Strategic Change, Vol. 26, No. 5, pp. 471-480. doi: $10.1002 /$ jsc. 2147.

$\varnothing$ Ines, S. et al. (2017), 'Blockchain in government: Benefits and implications of distributed ledger technology for information sharing', Government Information Quarterly, Vol. 34, pp. 1-10. doi: 10.1016/j.giq.2017.09.007.

Ouaddah, A. et al. (2016), 'FairAccess: a new Blockchain-based access control framework for the Internet of Things', Security and Communication Networks, Vol. 9, No. 18, pp. 5943-5964. doi: 10.1002/sec.1748.

Ouyang, X. et al. (2017), 'Preliminary Applications of Blockchain Technique in Large Consumers Direct Power Trading', Zhongguo Dianji Gongcheng Xuebao/Proceedings of the Chinese Society of Electrical Engineering, Vol. 37, No. 13, pp. 3737-3745. doi: 10.13334/j.0258-8013.pcsee.170370.

Pachaiyappan, V.;Kasturi, R. (2018), 'Block Chain Technology ( DLT Technique) for KYC in FinTech Domain: A Survey',International Journal of Pure and Applied Mathematics, Vol. 119, No. 10, pp. 259-265.

Park, L. W. et al. (2018), 'A sustainable home energy prosumer-chain methodology with energy tags over the blockchain',
Sustainability (Switzerland), Vol. 10, No. 3, pp. 1-18. doi: 10.3390/su10030658.

Peck, M. E.; Wagman, D. (2017), 'Energy trading for fun and profit buy your neighbor's rooftop solar power or sell your own-it'll all be on a blockchain', IEEE Spectrum, Vol. 54, No. 10, pp. 56-61. doi: 10.1109/MSPEC.2017.8048842.

Pieroni, A. et al. (2018), 'Smarter City: Smart Energy Grid based on Blockchain Technology', International Journal on Advanced Science, Engineering and Information Technology, Vol. 8, No. 1, p. 298. doi: 10.18517/ijaseit.8.1.4954.

Ping, J. et al. (2017), 'Decentralized Transactive Mechanism in Distribution Network Based on Smart Contract', Zhongguo Dianji Gongcheng Xuebao/Proceedings of the Chinese Society of Electrical Engineering, Vol. 37, No. 13, pp. 3682-3690. doi: 10.13334/j.0258-8013.pcsee.170374.

Pop, C. et al. (2018), 'Blockchain based decentralized management of demand response programs in smart energy grids', Sensors (Switzerland), Vol. 18, No. 1. doi: 10.3390/ s18010162.

Püttgen, F.; Kaulartz, M. (2017), 'Versicherung 4.0', ERA Forum, Vol. 18, No. 2, pp. 249-262. doi: 10.1007/s12027-0170479-y.

Rozario, A. M.; Vasarhelyi, M. A. (2018), 'Auditing with Smart Contracts', The International Journal of Digital Accounting Research, Vol. 18, pp. 1-27. doi: 10.4192/1577-8517-v18.

Savelyev, A. (2018), 'Copyright in the blockchain era: Promises and challenges', Computer Law and Security Review, Vol. 34, No. 3, pp. 550-561. · doi: 10.1016/j.clsr.2017.11.008.

Scott, B. et al. (2017), 'Exploring the rise of blockchain technology: Towards distributed collaborative organizations', Strategic Change, Vol. 26, No. 5, pp. 423-428. doi: 10.1002/ jsc. 2142.

Sharma, P. K.; Park, J. H. (2018), 'Blockchain based Hybrid Network Architecture for the Smart City', Future Generation Computer Systems, Vol. 86, pp. 650-655. doi: 10.1016/j.future.2018.04.060.

Sharma,P. K.; Chen, M.-Y.; Park, J. H. (2017), 'A Software Defined Fog Node based Distributed Blockchain Cloud Architecture for IoT', IEEE Access, Vol. 3536, No. c. doi: 10.1109/ ACCESS.2017.2757955.

Sharma, P. K.; Moon, S. Y.; Park, J. H. (2017), 'Block-VN: A distributed blockchain based vehicular network architecture in smart city', Journal of Information Processing Systems, Vol. 13, No. 1, pp. 184-195. doi: 10.3745/JIPS.03.0065.

Sharma, P. K.; Singh, S. et al. (2017), 'DistBlockNet: A Distributed Blockchains-Based Secure SDN Architecture for loT Networks', IEEE Communications Magazine, Vol. 55, No. 9, pp. 78-85. doi: 10.1109/MCOM.2017.1700041. 
She, W. et al. (2017), 'Virtual Power Plant Operation and Scheduling Model Based on Energy Blockchain Network', Zhongguo Dianji Gongcheng Xuebao/Proceedings of the Chinese Society of Electrical Engineering, Vol. 37, No. 13, pp. 3729-3736. doi: 10.13334/j.0258-8013.pcsee.170364.

Shermin, V. (2017), 'Disrupting governance with blockchains and smart contracts', Strategic Change, Vol. 26, No. 5, pp. 499-509. doi: 10.1002/jsc.2150.

Shi, Q. et al. (2017), 'Interprovincial generation rights trading model based on blockchain technology', Electric Power Construction, Vol. 38, No. 9, pp. 15-23. doi: 10.3969/j. issn.1000-7229.2017.09.003.

Sikorski, J. J. et al. (2017), 'Blockchain technology in the chemical industry: Machine-to-machine electricity market', Applied Energy, Vol. 195, pp. 234-246. doi: 10.1016/j.apenergy.2017.03.039.

Stein, S. (2018),'Blockchain engineers are in demand', available at: https://techcrunch.com/2018/02/14/blockchain-engineers-are-in-demand/ (access 7 Jan. 2018).

Sullivan, C.; Burger, E. (2017), 'E-residency and blockchain', Computer Law \& Security Review, Vol. 33, No. 4, pp. 470-481. doi: 10.1016/J.CLSR.2017.03.016.

Sundhararajan, M. et al. (2018), 'Artificial intelligent techniques and its applications', Journal of Intelligent and Fuzzy Systems, Vol. 34, No. 2, pp. 755-760. doi: 10.3233/JIFS-169369.

Swan, M. (2015), 'Blockchain Thinking: The Brain as a Decentralized Autonomous Corporation', IEEE Technology and Society Magazine, Vol. 34, pp. 41-52. doi: 10.1109/ MTS.2015.2494358.

Tai, X. et al. (2016), 'Electricity transactions and congestion management based on blockchain in energy internet', Dianwang Jishu/Power System Technology, Vol. 40, No. 12, pp. 3630-3638. doi: 10.13335/j.1000-3673.pst.2016.12.002.

Tan, A. W. K. et al. (2018), 'A blockchain model for less container load operations in China', International Journal of Information Systems and Supply Chain Management, Vol. 11, No. 1, pp. 39-53. doi: 10.4018/IJISSCM.2018040103.

Toyoda, K. et al. (2017), 'A Novel Blockchain-Based Product Ownership Management System (POMS) for Anti-Counterfeits in The Post Supply Chain', IEEE Access, Vol. 5, pp. 1746517477. doi: 10.1109/ACCESS.2017.2720760.

Tschorsch, F. (2016), 'Bitcoin and Beyond : A Technical Survey on Decentralized Digital Currencies', IEEE Communications Surveys \& Tutorials, Vol. 18, No. 3, pp. 2084-2123. doi: 10.1109/COMST.2016.2535718.

Wang, F.-Y.; Zhang, J. (2017), 'Internet of Minds: The Concept, Issues and Platforms', Zidonghua Xuebao/Acta Automatica Sinica, Vol. 43, No. 12, pp. 2061-2070. doi: 10.16383/j. aas.2017.y000006.
Wang, J. et al. (2018), 'A Blockchain based Privacy-Preserving Incentive Mechanism in Crowdsensing Applications', IEEE Access, Vol. 6, pp. 17545 -17556. doi: 10.1109/ACCESS.2018.2805837.

Wu, G. et al. (2017), 'Research on the Application of Blockchain in the Integrated Demand Response Resource Transaction', Zhongguo Dianji Gongcheng Xuebao/Proceedings of the Chinese Society of Electrical Engineering, Vol. 37, No. 13, pp. 3717-3728. doi: 10.13334/j.0258-8013.pcsee.170284.

Xia, Q.; Sifah, E. B; Smahi, S. et al. (2017), 'BBDS: Blockchain-Based Data Sharing for Electronic Medical Records in Cloud Environments', Information, Vol. 8, No. 2, p. 44. doi: 10.3390/ info8020044.

Xia, Q.; Sifah, E. B.; Asamoah, K. O. et al. (2017), 'MeDShare: Trust-Less Medical Data Sharing among Cloud Service Providers via Blockchain', IEEE Access, Vol. 5, pp. 14757-14767. doi: 10.1109/ACCESS.2017.2730843.

Yang, D. et al. (2017), 'Developing Status and Prospect Analysis of Blockchain in Energy Internet', Zhongguo Dianji Gongcheng Xuebao/Proceedings of the Chinese Society of Electrical Engineering, Vol. 37, No. 13, pp. 3664-3671. doi: 10.13334/j.0258-8013.pcsee.170201.

Yang, X. et al. (2017), 'Blockchain-based Automated Demand Response Method for Energy Storage System in an Energy Local Network', Zhongguo Dianji Gongcheng Xuebao/ Proceedings of the Chinese Society of Electrical Engineering, Vol. 37, No. 13, pp. 3703-3716. doi: 10.13334/j.0258-8013. pcsee. 170387

Ying, W. et al. (2018), 'Digital enablement of blockchain: Evidence from HNA group', International Journal of Information Management, Vol. 39, pp. 1-4. doi: 10.1016/j.ijinfomgt.2017.10.004.

Yli-Huumo, J. et al.(2016), 'Where Is Current Research on Blockchain Technology?-A Systematic Review', PLOS ONE. Edited by H. Song. Public Library of Science, Vol. 11, No. 10, p. e0163477. doi: 10.1371/journal.pone.0163477.

Yuan, R. et al. (2018), 'ShadowEth: Private Smart Contract on Public Blockchain', Journal of Computer Science and Technology, Vol. 33, No. 3, pp. 542-556. doi: 10.1007/s11390-0181839-y.

Yuan, Y.; Wang, F.-Y. (2016), 'Blockchain: The state of the art and future trends', Zidonghua Xuebao/Acta Automatica Sinica. Science Press, Vol. 42, No. 4, pp. 481-494. doi: 10.16383/j. aas.2016.c160158.

Yue, X. et al. (2016), 'Healthcare Data Gateways: Found Healthcare Intelligence on Blockchain with Novel Privacy Risk Control', Journal of Medical Systems, Vol. 40, No. 10, p. 218. doi: 10.1007/s10916-016-0574-6. 
Zamani, E. D.; Giaglis, G. M. (2018), 'With a little help from the miners: distributed ledger technology and market disintermediation', Industrial Management \& Data Systems, Vol. 118, No. 3, pp. 637-652. doi: 10.1108/IMDS-05-2017-0231.

Zeilinger, M. (2018), 'Digital Art as "Monetised Graphics": Enforcing Intellectual Property on the Blockchain', Philosophy and Technology, Vol. 31, No. 1, pp. 15-41. doi: 10.1007/ s13347-016-0243-1.

Zeng, M. et al. (2017), 'Primarily Research for Multi Module Cooperative Autonomous Mode of Energy Internet Under Blockchain Framework', Zhongguo Dianji Gongcheng Xuebao/ Proceedings of the Chinese Society of Electrical Engineering, Vol. 37, No. 13, p. 3672-3681. doi: 10.13334/j.0258-8013.pcsee.162432.

Zhang, J. et al. (2016), 'A Secure System for Pervasive Social Network-Based Healthcare', IEEE Access, Vol. 4, pp. 92399250. doi: 10.1109/ACCESS.2016.2645904.

Zhang, N. et al. (2016), 'Blockchain technique in the Energy Internet: preliminary research framework and typical applications', Zhongguo Dianji Gongcheng Xuebao/Proceedings of the Chinese Society of Electrical Engineering, Vol. 36, No. 15, pp. 4011-4022. doi: 10.13334/j.0258-8013.pcsee.161311.
Zhang, Y.; Wen, J. (2017), 'The loT electric business model: Using blockchain technology for the internet of things', Peer-to-Peer Networking and Applications, Vol. 10, No. 4, pp. 983-994. doi: 10.1007/s12083-016-0456-1.

Zhao, H. et al. (2015), 'Data integrity protection method for microorganism sampling robots based on blockchain technology', Huazhong Keji Daxue Xuebao (Ziran Kexue Ban)/Journal of Huazhong University of Science and Technology (Natural Science Edition), Vol. 43, pp. 216-219. doi: 10.13245/j. hust.15S1052.

Zhao, Y. et al. (2018), 'Secure Pub-Sub: Blockchain-Based Fair Payment with Reputation for Reliable Cyber Physical Systems', IEEE Access, Vol. 6, pp. 12295-12303. doi: 10.1109/ACCESS.2018.2799205.

Zhong, R. Y. et al. (2017), 'IoT-enabled Smart Factory Visibility and Traceability Using Laser-scanners', Procedia Manufacturing, Vol.10, pp. 1-14. doi: 10.1016/j.promfg.2017.07.103.

Ziegeldorf, J. H. et al. (2018), 'Secure and anonymous decentralized Bitcoin mixing', Future Generation Computer Systems, Vol. 80, pp. 448-466. doi: 10.1016/j.future.2016.05.018.

Received: 18 Out 2018

Approved: 07 Nov 2018

DOI: 10.14488/BJOPM.2019.v16.n4.a12

How to cite: Meiriño, M. J.; Méxas, M. P.; Faria, A. V. et al. (2019), “Blockchain technology applications: a literature review", Brazilian Journal of Operations \& Production Management, Vol. 16, No. 4, pp. 672-684, available from: https://bjopm.emnuvens.com.br/bjopm/article/view/585 (access year month day). 